\title{
Genetic Diversity of Seven Deciduous Azalea Species (Rhododendron spp. section Pentanthera) Native to the Eastern United States
}

\author{
Matthew Chappell \\ Department of Horticulture, University of Georgia, 211 Hoke Smith Building, Athens, GA 30602 \\ Carol Robacker ${ }^{1}$ \\ Department of Horticulture, University of Georgia, 1109 Experiment Street, Griffin, GA 30223 \\ Tracie M. Jenkins \\ Department of Entomology, University of Georgia, 1109 Experiment Street, Griffin, GA 30223
}

\begin{abstract}
Additional Index words. AFLP markers, introgression, among-population diversity, within-population diversity, AMOVA, phenogram

Abstract. Despite the ecologic and economic importance of native deciduous azaleas (Rhododendron L. section Pentanthera G. Don), our understanding of interspecific variation of North American deciduous azalea species comes principally from morphologic studies. Furthermore, little is known concerning intraspecific or interpopulation genetic variation. With ever-increasing loss and fragmentation of native azalea habitat in the eastern United States due to anthropogenic activity, it is imperative that an understanding of natural genetic variation among and within species and populations is acquired. The present study addresses questions of genetic diversity through the use of amplified fragment length polymorphism (AFLP) analysis. Twenty-five populations of seven species of native azalea were analyzed using three primer pairs that amplified a total of 417 bands. Based on analysis of molecular variance (AMOVA) and estimates of Nei's coefficients of gene diversity $\left(H_{\mathrm{S}}, H_{\mathrm{T}}\right.$, and $\left.G_{\mathrm{ST}}\right)$, the majority of variation found in deciduous azalea occurs within populations. Variation both among species and among population was low, likely the effect of common ancestry as well as frequent introgression among members (and populations) of section Pentanthera. The latter was evident in four populations of $R$. prunifolium (Small) Millais and $R$. canescens (Michaux) Sweet that were highly related to $R$. austrinum (Small) Rehder and $R$. viscosum (L.) Torrey, respectively. Despite these outliers, most populations were grouped into species based on Nei's unbiased genetic distances viewed as an unweighted pair group method with arithmetic mean (UPGMA) phenogram. The significance of these results is discussed in relation to breeding in section Pentanthera.
\end{abstract}

Deciduous azalea species are indigenous to the eastern United States from southeastern Canada southwestward to eastern Texas and east to the Atlantic coast. The deciduous azalea is an outstanding spring-summer blooming woody ornamental and, along with evergreen azaleas, is a common plant in eastern U.S. landscapes (Galle, 1987). The level of genetic diversity among species has been addressed in a previous study (Scheiber et al., 2000), yet no research has described the amount of genetic diversity among populations of a single species or within individual populations. This research was conducted to answer these questions.

Scharff (1911) postulated that the introduction and migration of deciduous azaleas to North America occurred from Asia, via the Bering Strait land bridge, in the early Tertiary to prePliocene periods. Despite the assumed 5 to 65 million years since, little change was observed in chromosome number and morphology when members of section Pentanthera were compared with possible Asian founder species Rhododendron schlippenbachii Maximowicz from Korea, Rhododendron molle Blume from China, and Rhododendron japonicum (Gray) Sur. from Japan (Li, 1957; Sax, 1930). Rehder (1921) success-

Received for publication 27 Apr. 2007. Accepted for publication 8 Feb. 2008. We thank Drs. Noelle Barkley, Rob Dean, Melanie Newman, and Zhenbang Chen for assistance with AFLP methodology and data analysis.

${ }^{1}$ Corresponding author. E-mail: croback@griffin.uga.edu. fully hybridized Rhododendron luteum Sweet (eastern Europe) and Rhododendron canadense (L.) Torr. (eastern Canadanortheast United States). All Rhododendron spp. within section Pentanthera have subsequently been hybridized (Galle, 1967; Skinner, 1961; Wherry, 1943). The results of chromosome and breeding studies indicate a high degree of chromosome stability within Rhododendron spp. section Pentanthera. They also suggest species identity is maintained through geographic isolation via habitat preference and temporal patterns of flowering rather than interspecific crossing barriers.

Kron et al. (1993) used chloroplast DNA markers to distinguish two species of deciduous azalea, Rhododendron canescens and Rhododendron flammeum (Michaux) Sargent and also to measure introgression in a hybrid swarm located at Stone Mountain, GA. Morphological markers were used to confirm results and measure the level of introgression within the population. In the hybrid population of $R$. canescens and $R$. flammeum, interspecific hybridization and introgression were confirmed in more than $75 \%$ of the surveyed individuals. This study verified the value of DNA-based studies to distinguish between species of deciduous azaleas and indicated that introgression in native azaleas could hamper genome-based studies of genetic diversity. Iqbal et al. (1995) proved the usefulness of whole-genome analysis to distinguish germplasm within the genus Rhododendron. They employed RAPD analysis to detect genetic relatedness of both evergreen and 
deciduous species and cultivars of Rhododendron and to test if RAPD analysis of Rhododendron spp. reflected their true genetic relationships. Using cluster analysis, species and cultivars were grouped as predicted based upon origin and known pedigree.

Scheiber et al. (2000) sequenced the entire internal transcribed spacer (ITS) region, including ITS1, ITS2, and the 5.8S subunit, of 16 members of Rhododendron section Pentanthera in an effort to group species on the basis of genetic similarity. The ITS region is unique in that it is transcribed yet untranslated; therefore, it is postulated to change freely via deletion or addition without altering gene products. This study was the first to focus on members of section Pentanthera, and results indicated extremely little variation in ITS sequence, ranging from $0.00 \%$ to $1.67 \%$. Studies among species within section Pentanthera are needed that will sample total genomic variation. AFLP has this ability as it produces a large number of polymorphisms when no prior sequence information is known (Vos et al., 1995), and results are highly reproducible (Jones et al., 1997). For example, Barker et al. (1999) found 170 polymorphic bands with 20 RAPD primers in Salix L., yet using four AFLP primers they found 645 polymorphic bands. AFLP is also highly reproducible. For example, Winfield et al. (1998), in an AFLP analysis of black poplar (Populus nigra L.), found that, for five trials at five varying laboratories, banding patterns were $97.6 \%$ to $100 \%$ similar.

A naturally occurring plant population is determined to be composed of a single species if all individuals within that population resemble one species in the vast majority of phenotypically measurable traits. Results presented by Kron et al. (1993) suggest introgression could be a major obstacle in any genome-based analysis of native azalea species. Introgression is the infiltration of genetic material from one species into the germplasm of another through repeated backcrossing (Anderson, 1949) and can result in the selection of naturally occurring populations that resemble one species but contain genetic material from another (or several other) species. This phenomenon can confound results of genetic studies by creating a significant downward bias in genetic diversity estimates among species and a significant upward bias in genetic diversity within populations. Many native azalea populations contain obvious hybrid individuals as well as individuals that resemble one to several species (Galle, 1987). A far fewer number of populations contain only individuals that morphologically resemble accepted taxonomic keys. Therefore, in this study, populations were selected after rigorous examination of morphologic characters across each population, based upon the accepted morphologic key presented by Kron (1993). Thereafter, we used AFLP analysis to ascertain the level of genetic diversity among and within naturally occurring species and populations of seven species of deciduous azaleas.

\section{Materials and Methods}

Plant material and collection. Seven species of deciduous Rhododendron spp. section Pentanthera native to the eastern United States were included in this study. The species included Rhododendron austrinum, Rhododendron calendulaceum (Michaux) Torrey, R. canescens, R. flammeum, Rhododendron atlanticum Ashe, Rhododendron prunifolium, and Rhododendron viscosum. Three to six populations per species (Table 1) were selected as viable collection sites based on three parameters: isolation from other Rhododendron section Pentanthera species or hybrid swarms, size of population with a minimum of 15 individuals in the population of interest, and morphologic characteristics. An extensive morphologic key by Kron (1993) was used to identify populations of a single species with no hybrid individuals. Traits including leaf shape and size, pubescence patterns, vein patterns, stem color, stipules, petiole length, flower color, flowering time, seed pod pubescence and size, bud scale patterns and color, and growth habit and habitat were examined at three intervals over a 1-year period before collection. Leaf samples were collected from six individuals per population (Kalinowski, 2005) $\approx 7-14 \mathrm{~d}$ after leaf emergence yet before complete leaf expansion. Selection of individual plants to sample was determined by constructing a grid pattern of each population and thereafter collecting plants evenly distributed throughout the entire population. Collected leaf tissues were individually stored at $-70^{\circ} \mathrm{C}$.

AFLP PROCEdure. The EZNA ${ }^{\circledR}$ High-Performance DNA extraction kit (Omega Bio-Tek, Doraville, GA) and corresponding protocol were used in total genomic DNA extraction from $100 \mathrm{mg}$ of frozen leaf tissue. DNA was quantified using a spectrofluorometer and 1\% agarose gel with Low DNA Mass Ladder $^{\mathrm{TM}}$ (Invitrogen ${ }^{\mathrm{TM}}$, Carlsbad, CA) while simultaneously checking for quality (shearing). Subsequently, genomic DNA was stored at $-20{ }^{\circ} \mathrm{C}$ in sterile deionized water. Restriction/ digestion, ligation, and preselective amplification (Table 2) of genomic DNA were carried out using the IRDye ${ }^{\mathrm{TM}}$ AFLP Template Preparation Kit (LI-COR, Lincoln, NE). All polymerase chain reactions (PCR) were carried out in a PerkinElmer (Waltham, MA) Model 9600 Thermal Cycler ${ }^{\circledR}$. Thirty primer pairs (Table 2) were screened on two individuals of each species included in this study. Three primer pairs, E-ACA/MCTG, E-ACT/M-CAC, and E-AGG/M-CAT, were selected based upon number of polymorphic bands visualized on a gel and repeatability of band presence over three trials. Only EcoRI primers $(100 \mu \mathrm{M})$ with fluorescence at $700 \mathrm{~nm}$ (LI-COR) were selected because band intensity was extremely low for all 800 nm primers.

Selective amplification was carried out on all individuals with each of the three selected primer pairs. Reactions were carried out in 96-well PCR plates in $12 \mu \mathrm{L}$ volume containing: $1.5 \mathrm{~mm} \mathrm{MgCl}_{2}$ (Promega, Madison, WI), 1 U GOTaq ${ }^{\circledR}$ DNA polymerase (Promega), 0.83× GOTaq buffer (Promega), 200 $\mu \mathrm{M}$ each deoxynucleotide triphosphate (dNTP) (Promega), $5 \mu \mathrm{M}$ $M s e \mathrm{I}$ primer, $5 \mu \mathrm{M} E c o$ RI primer, and $4 \mu \mathrm{L}$ of template DNA from the preselective amplification stage. PCR conditions for selective amplification were set based on the LI-COR AFLP protocol. Following completion of the selective amplification PCR program, products were immediately denatured by adding $3 \mu \mathrm{L}$ of Blue Stop Solution ${ }^{\circledR}$ (LI-COR) to each well and heating to $94{ }^{\circ} \mathrm{C}$ for $4 \mathrm{~min}$. Samples were then cooled to $4{ }^{\circ} \mathrm{C}$ and placed on ice or in a refrigerator until they were loaded into gels.

Gels were cast using LI-COR 25-cm glass plates with 0.25 mm spacers. Twenty milliliters of $6.5 \% \mathrm{~KB}$ Plus acrylamide gel solution was combined with $150 \mu \mathrm{L}$ of ammonium persulfate and $15 \mu \mathrm{L}$ of TEMED. DNA was loaded at a volume of $0.4 \mu \mathrm{L}$ per well. Each gel included all individuals from a single species-primer pair combination. Each gel also included two standards to enable efficient and reliable gel comparison in the scoring process. The first standard employed was a LI-COR IRDye $^{\circledR} 50-700$ size standard, placed on the outside two lanes of each gel. The second standard was a panel of each species, 
Table 1. Locations of Rhododendron section Pentanthera populations collected, grouped by species. ${ }^{\mathrm{z}}$

\begin{tabular}{|c|c|c|c|c|c|}
\hline Population & Rhododendron & & Sample & & \\
\hline no. & species & Location & nos. & Latitude & Longitude \\
\hline 1 & R. austrinum & Holmes County, FL & $1-6$ & $30^{\circ} 42^{\prime}$ & $85^{\circ} 55^{\prime}$ \\
\hline 2 & R. austrinum & Washington County, FL & $7-12$ & $30^{\circ} 31^{\prime}$ & $85^{\circ} 53^{\prime}$ \\
\hline 3 & R. austrinum & Vernon, FL & $13-18$ & $30^{\circ} 37^{\prime}$ & $85^{\circ} 41^{\prime}$ \\
\hline 4 & R. prunifolium & Georgetown, GA & $19-24$ & $31^{\circ} 53^{\prime}$ & $85^{\circ} 6^{\prime}$ \\
\hline 5 & R. prunifolium & Morris-Quitman County, GA & $25-30$ & $31^{\circ} 46^{\prime}$ & $85^{\circ} 1^{\prime}$ \\
\hline 6 & R. prunifolium & Randolph County, GA & $31-36$ & $31^{\circ} 55^{\prime}$ & $84^{\circ} 48^{\prime}$ \\
\hline 7 & R. prunifolium & Randolph County, GA & $37-42$ & $32^{\circ} 4^{\prime}$ & $84^{\circ} 54^{\prime}$ \\
\hline 8 & R. prunifolium & Harris County, GA & $43-48$ & $32^{\circ} 46^{\prime}$ & $84^{\circ} 55^{\prime}$ \\
\hline 9 & R. prunifolium & West Point, GA & $49-54$ & $32^{\circ} 53^{\prime}$ & $85^{\circ} 10^{\prime}$ \\
\hline 10 & R. calendulaceum & Amherst County, VA & $55-60$ & $37^{\circ} 28^{\prime}$ & $79^{\circ} 34^{\prime}$ \\
\hline 11 & R. calendulaceum & Towns County, GA & $61-66$ & $34^{\circ} 51^{\prime}$ & $83^{\circ} 48^{\prime}$ \\
\hline 12 & R. calendulaceum & Macon County, NC & $67-72$ & $35^{\circ} 10^{\prime}$ & $83^{\circ} 34^{\prime}$ \\
\hline 13 & R. viscosum & Bullock County, GA & $73-78$ & $32^{\circ} 21^{\prime}$ & $81^{\circ} 51^{\prime}$ \\
\hline 14 & R. viscosum & Essex County, VA & $79-84$ & $37^{\circ} 59^{\prime}$ & $76^{\circ} 56^{\prime}$ \\
\hline 15 & R. viscosum & Meriwether County, GA & $85-90$ & $32^{\circ} 58^{\prime}$ & $84^{\circ} 37^{\prime}$ \\
\hline 16 & R. canescens & Bullock County, GA & $91-96$ & $32^{\circ} 18^{\prime}$ & $81^{\circ} 49^{\prime}$ \\
\hline 17 & R. canescens & Baldwin County, GA & $97-102$ & $33^{\circ} 8^{\prime}$ & $83^{\circ} 6^{\prime}$ \\
\hline 18 & R. canescens & Lee County, AL & $103-108$ & $32^{\circ} 41^{\prime}$ & $85^{\circ} 22^{\prime}$ \\
\hline 19 & $R$. canescens & Spalding County, GA & $109-114$ & $33^{\circ} 17^{\prime}$ & $84^{\circ} 5^{\prime}$ \\
\hline 20 & R. atlanticum & Dinwiddie County, VA & $115-120$ & $36^{\circ} 58^{\prime}$ & $77^{\circ} 35^{\prime}$ \\
\hline 21 & R. atlanticum & Carteret County, NC & $121-126$ & $34^{\circ} 45^{\prime}$ & $76^{\circ} 46^{\prime}$ \\
\hline 22 & R. atlanticum & Florence County, SC & $127-132$ & $34^{\circ} 15^{\prime}$ & $79^{\circ} 35^{\prime}$ \\
\hline 23 & R. flammeum & Milledgeville, GA & $133-138$ & $33^{\circ} 0^{\prime}$ & $83^{\circ} 9^{\prime}$ \\
\hline 24 & R. flammeum & Thomaston, GA & $139-144$ & $32^{\circ} 50^{\prime}$ & $84^{\circ} 19^{\prime}$ \\
\hline 25 & R. flammeum & Fulton County, GA & $145-150$ & $33^{\circ} 39^{\prime}$ & $84^{\circ} 30^{\prime}$ \\
\hline
\end{tabular}

${ }^{\mathrm{z}}$ Each population is numbered in succession and includes six individual plant samples, also listed in consecutive order.

with one individual of each species included in all gels. Extraction and analysis was repeated in thirty-three percent of the individuals to ensure repeatability of banding patterns.

Gels were run on a LI-COR model 4300S DNA Analysis System using the SagaLite ${ }^{\circledR}$ software package (LI-COR) with laser focus adjusted on a run-by-run basis to optimize performance. Run length was set to $4 \mathrm{~h}$ with KBplus standard electrophoresis conditions. Standard power and temperature settings were used with the exception of voltage, which was reduced to 1000 to allow for increased lowbase pair band separation. Gel images produced by SagaLite ${ }^{\circledR}$ were graphically adjusted within the program and exported to GelBuddy (Zerr and Henikoff, 2005) whereby gels were graphically aligned using monomorphic banding patterns. Image files were then exported to Adobe Photoshop ${ }^{\circledR}$ CS2 (Adobe Systems, San Jose, CA), and all gel images from a single primer pair merged into a single graphics file. Individual gel images were aligned using three standards: the LI-COR IRDye ${ }^{\circledR}$ 50-700 size standard, the panel lanes that included one sample of each species, and the monomorphic bands shared by all species. The resulting single graphics file was used in the scoring of gels.

Data ANalysis. Bands were manually scored in binary format as present (1) or absent (0), and values recorded in Excel $^{\circledR}$ (Microsoft, Redmond, WA), including monomorphic bands. Data from the three primer pair combinations required a 3 -fold increase in the quantity of columns available in Excel 2003. Therefore, GS-Calc version 7.1 (JPS Development, Palmer Lake, CO) was used to combine data sets from the three primer pairs into a single data set that was manipulated as needed for individual data analysis programs.

PopGene version 3.2 (Yeh et al., 1999) was used to calculate Nei's genetic diversity (Nei, 1987) and percentage of polymorphic loci. Settings for analysis included a significance level of $P \leq 0.05$, seven groups (one for each species), and 10,000

Table 2. List of adaptors and primers screened and used in this study to characterize the amplification fragment length polymorphism (AFLP) band patterns in seven Rhododendron spp.

\begin{tabular}{|c|c|c|}
\hline & MseI site & EcoRI site \\
\hline \multirow[t]{2}{*}{ Adaptors } & 5'-TACTCAGGACTCAT-3' & 5' -CTCGTAGACTGCGTACC-3' $^{\prime}$ \\
\hline & 5'-GACGATGAGTCCTGAG-3' & 5'-AATTGGTACGCAGTCTAC-3' \\
\hline $\begin{array}{l}\text { Pre-selective amplification } \\
\text { primers }\end{array}$ & 5'-GATGAGTCCTGAGTAAC-3' & 5'-GACTGCGTACCAATTCA-3' \\
\hline \multirow{5}{*}{$\begin{array}{l}\text { Selective amplification primers } \\
\text { screened }\end{array}$} & MseI-CTT & EcoRI-ACT-700 z \\
\hline & MseI-CAC & EcoRI-ACA-700 \\
\hline & MseI-CAT & EcoRI-ACC-800 \\
\hline & MseI-CTA & EcoRI-AGC-800 \\
\hline & & EcoRI-AAC-800 \\
\hline \multirow{2}{*}{$\begin{array}{l}\text { Selective amplification primer } \\
\text { sets }^{\mathrm{y}}\end{array}$} & MseI-CTG & EcoRI-ACA-700 \\
\hline & MseI-CAC & EcoRI-ACT-700 \\
\hline
\end{tabular}

${ }^{\mathrm{z} E c o ~ R I ~ p r i m e r s ~ w e r e ~ l a b e l e d ~ w i t h ~ o n e ~ o f ~ t w o ~ L I-C O R ~(L i n c o l n, ~ N E) ~ f l u o r e s c e n t ~ t a g s ~ w i t h ~ p e a k ~ f l u o r e s c e n c e ~ a t ~} 700 \mathrm{or} 800 \mathrm{~nm}$.

${ }^{\mathrm{y}}$ Three primer sets selected from 30 screened primer pairs. 
simulations. A matrix of Nei's unbiased genetic distances (Nei, 1978) was calculated by PopGene version 3.2 using all markers, including monomorphs. Nei's unbiased genetic distance is the most accurate and reliable estimate of genetic diversity when population sizes are small (Nei, 1978). A dendrogram, based on Nei's unbiased genetic distance matrix (Nei, 1978), was constructed to determine the extant relationships among the 25 surveyed populations using NTSYS (Rohlf, 1992). Genetic similarity was determined by the Dice similarity coefficient (\%) and neighbor-joining analysis (Saitou and Nei, 1987) of extant relationships.

Analyses of molecular variance was calculated among species using Arlequin version 2.000 (Schneider et al., 2000) to determine the hierarchical partitioning of genetic variability among all species, populations within a single species, and within each population. Hickory version 1.0.4 (Holsinger et al., 2002) was used to calculate panmictic heterozygosity based on mean allele frequencies $\left(H_{\mathrm{T}}\right)$, average panmictic heterozygosity within each population $\left(H_{\mathrm{S}}\right)$, and the Bayesian analog of Nei's $G_{\mathrm{ST}}$ (Holsinger, 1999). Data were analyzed among and within species using a 250,000 burn-in and 500,000 randomizations.

\section{Results and Discussion}

LEVEL OF POLYMORPHISM. Three AFLP primer combinations (Table 2) amplified a total of 417 polymorphic bands (72 monomorphic bands). The average repeatability of AFLP fragments across two replications was $97.4 \%$ (data not shown). The primer pair $M s e I-C T G / E c o R I-A C A$ amplified 142 polymorphic bands (22 monomorphic bands); the primer pair MseI-CAC/EcoRI-ACT amplified 134 polymorphic bands (27 monomorphic bands); and the primer pair MseI-CAT/ EcoRI-AGG amplified 141 polymorphic bands (23 monomorphic bands). Unbiased genetic distance matrices were calculated from each of the three primer pairs and compared by Mantle test in three possible combinations. Results indicate that the information generated by each of the primer pairs was consistent ( $r>0.9, P<0.01)$ across primer combinations. The percentage of polymorphic loci across all species was $89.69 \%$ (Table 3). Within species, polymorphic band percentages ranged from $86.81 \%$ to $91.85 \%$. The high degree of polymorphism is not due to a single species or population within a species, but rather polymorphic loci are spread evenly across all species and individual populations.

Table 3. Percentage of polymorphic loci, average genetic diversity within populations $\left(H_{\mathrm{S}}\right)$, average genetic diversity within species $\left(H_{\mathrm{T}}\right)$, and proportion of species genetic diversity attributed to among-population variation $\left(G_{\mathrm{ST}}\right)$ for seven species of Rhododendron section Pentanthera.

\begin{tabular}{lcccc}
\hline Species & $\begin{array}{c}\text { Polymorphic } \\
\text { loci (\%) }\end{array}$ & $H_{\mathrm{S}}$ & $H_{\mathrm{T}}$ & $G_{\mathrm{ST}}$ \\
\hline$R$. atlanticum & 87.53 & 0.3287 & 0.3661 & 0.1021 \\
$R$. austrinum & 86.81 & 0.2931 & 0.3420 & 0.1431 \\
$R$. calendulaceum & 90.27 & 0.3479 & 0.3949 & 0.1190 \\
$R$. canescens & 91.85 & 0.3107 & 0.4023 & 0.2278 \\
$R$. flammeum & 89.69 & 0.3434 & 0.3789 & 0.0937 \\
$R$. prunifolium & 89.11 & 0.3011 & 0.4066 & 0.2594 \\
$R$. viscosum & 88.25 & 0.2910 & 0.3572 & 0.1853 \\
Overall & 89.69 & 0.3109 & 0.4372 & 0.2890 \\
\hline
\end{tabular}

Diversity AMONg SPECIES. Based on AMOVA results, the proportion of variation among species is only $14 \%$ (Table 4). Studies by Kurashige et al. (2001) and Scheiber et al. (2000) present similar findings as to the low level of genetic diversity among members of Rhododendron spp. section Pentanthera. In the latter study, the entire ITS region was analyzed to determine genetic relatedness of members of Rhododendron spp. section Pentanthera. The ITS region has been used to study interspecific genetic structure because subtle genetic differences at the base-pair level have been observed. Therefore, the agreement of ITS data and AFLP data from this study indicate that members of Rhododendron spp. section Pentanthera are highly related and possibly derived from a common ancestor. Sax (1930) and Li (1957) noted considerable chromosome similarity among possible Asian founder species and North American native azalea species. These included $R$. molle from China and $R$. japonicum from Japan that are in section Pentanthera, and Rhododendron schlippenbachii from Korea that is in section Sciadorhodion Rehder. Further research, such as study of chloroplast DNA, is needed to conclusively determine the ancestry of U.S. native deciduous azalea species. Alone, common ancestry is unlikely to explain all of the present-day genetic similarity among species since the proposed migration of section Pentanthera into North America 5 to 65 million years ago. The low proportion of genetic variation among species is likely a result of common ancestry coupled with an abnormally high level of naturally occurring interspecific hybridization and introgression events such as that deduced by Kron et al. (1993). Breeders should be aware of the effects of introgression when using plants collected in the wild as parents, such as confounding genetic ratios and the possibility of unexpected phenotypic characters in progeny of crosses.

Diversity AMONG POPUlations. The proportion of species genetic diversity attributed to among-population variation, $G_{\mathrm{ST}}$ $=1-\left(H_{\mathrm{S}} / H_{\mathrm{T}}\right)$, where $H_{\mathrm{S}}$ is the average genetic diversity within populations and $H_{\mathrm{T}}$ is the genetic diversity within species, is a critical indicator of genetic diversity at the population level. The proportion of total genetic diversity that occurs among populations overall species and loci $\left(G_{\mathrm{ST}}\right)$ was 0.29 , and that within each species ranged from 0.09 in $R$. flammeum to 0.26 in $R$. prunifolium (Table 3 ). The relatively low overall $G_{\mathrm{ST}}$ indicates that a low-to-marginal proportion of diversity $(29 \%)$ is observed among populations as opposed to a high level of diversity observed within populations $(71 \%)$. Low $G_{\text {ST }}$ values also indicate a high level of gene flow among populations, which tends to homogenize a species' genetic structure. This is expected as members of Rhododendron spp. section Pentanthera are entomophilously pollinated (Galle, 1987; Hamrick and Godt, 1996). Insect pollination leads to populations with a high level of genetic variation, while individuals within the

Table 4. Analysis of molecular variation (AMOVA) for seven Rhododendron spp. included in this study.

\begin{tabular}{lrcccc}
\hline Source of variation & df & \multicolumn{1}{c}{$\begin{array}{l}\text { Sum of } \\
\text { squares }\end{array}$} & $\begin{array}{c}\text { Variance } \\
\text { component }\end{array}$ & $\begin{array}{c}\text { Variance } \\
\text { (\%) }\end{array}$ & $P$ \\
\hline Among species & 6 & $2,248.74$ & 13.30 & 14.14 & $<0.05$ \\
Among populations & & & & & \\
$\quad$ within species & 18 & $1,702.94$ & 2.80 & 2.99 & $<0.05$ \\
Within populations & 125 & $9,722.33$ & 77.80 & 82.88 & $<0.05$ \\
Total & 149 & $13,674.01$ & 93.85 & & \\
\hline
\end{tabular}


population share a similar complement of alleles in similar frequencies (Falk et al., 2001; Hamrick and Godt, 1996). AMOVA (Table 4) supports $G_{\mathrm{ST}}$ values and indicates a high level of variation is observed within populations (83\%) and low proportion of variation among populations $(3 \% ; P<0.05)$. The relatively low $G_{\mathrm{ST}}$ value coupled with low proportion of variation among populations from AMOVA further indicates that individuals within populations are likely to be genetically distinct; however, each population contains a very similar complement of alleles in similar frequencies (Falk et al., 2001). Thus, from a breeding standpoint, the low percentage of among-population variation is important in the selection of parents. Within each species, individuals obtained from geographically isolated populations will not substantially increase allelic diversity in a breeding program.

Diversity Within populations. AMOVA and $G_{\text {ST }}$ values correspond to the proportion (percentage) of genetic variation partitioned among species, among populations, or within populations. $H_{\mathrm{S}}$ and $H_{\mathrm{T}}$ values, conversely, are a direct measure of diversity within populations and within species, respectively (Falk et al., 2001). $H_{\mathrm{S}}$ and $H_{\mathrm{T}}$ values offer insight into the actual level, rather than proportion, of genetic variation within populations and within each species.

The average genetic diversity within populations $\left(H_{\mathrm{S}}\right)$ was low to moderate for all species, ranging from 0.29 in $R$. austrinum and $R$. viscosum to 0.35 in $R$. calendulaceum (Table $3)$. A likely cause for lower average diversity in $R$. austrinum and $R$. viscosum is population size. All $R$. austrinum and $R$. viscosum populations surveyed inhabited a relatively small geographic area $\left(<0.7 \mathrm{~km}^{2}\right)$. The reduced geographic size of the populations allow for pollen to be easily transported among all individuals of the population, effectively reducing withinpopulation genetic diversity. This is unlike larger populations, where the migratory range of insects may only cover a portion of the entire population and, therefore, facilitate higher withinpopulation diversity. In addition to small population size, $R$. viscosum also has a flowering time 1-2 months later than any other species with the exception of $R$. prunifolium. The offset reproductive cycle, in comparison with other members of Rhododendron spp. section Pentanthera, reduced the potential of introgression with adjacent species in past generations that could lead to decreased diversity within populations $\left(H_{\mathrm{S}}\right)$.

The species with the highest average genetic diversity within populations $\left(H_{\mathrm{S}}\right), R$. calendulaceum $(0.35$; Table 3$)$, is the only tetraploid member of Rhododendron spp. section Pentanthera $(n=26,2 n=52)$. Li (1957) concluded, on the basis of differing sizes of chromosome complements, that $R$. calendulaceum is an allotetraploid, which may explain the higher within-population diversity. $R$. flammeum also has comparatively high genetic diversity within populations (0.34) and, interestingly, exhibits a high level of within-population phenotypic variability. Of all members of Rhododendron spp. section Pentanthera, $R$. canescens occupies the largest geographic range and inhabits the largest variety of habitats. As the habitats and bloom cycle of $R$. flammeum overlap with $R$. canescens, past introgression events, undetectable when assessing morphologic traits, may explain the observed variability. Kron (1993) documented this in a study involving natural populations of $R$. canescens, $R$. flammeum, and hybrids of the two species. It was discovered that, despite phenotypic assignment of an individual to $R$. flammeum, chloroplast DNA proved that the individual contained alleles from $R$. canescens. Because anthesis of
$R$. canescens typically precedes that of $R$. flammeum, pollen of $R$. canescens is available to pollinate $R$. flammeum flowers after its flowers open yet before anthesis (Kron, 1993).

Within-SPECIES DIVERSITY. Genetic diversity within species $\left(H_{\mathrm{T}}\right)$ was low to moderate, ranging from 0.34 in $R$. austrinum to 0.41 in $R$. prunifolium (Table 3 ). The relatively low level of within-species diversity of $R$. austrinum may be due to the small geographic range of the species and hence the short distances between population sites (Falk et al., 2001). No two populations were greater than $34 \mathrm{~km}$ apart, and populations from such close proximities are more likely to be highly related than distant populations. Rhododendron viscosum had similar within-species diversity (0.36) despite geographic distances between populations of at least $237 \mathrm{~km}$. Low species diversity in $R$. viscosum is most likely a direct result of disjointed flowering time. In this study, collection of $R$. viscosum was also conducted outside the geographic range of $R$. prunifolium to minimize the potential of contamination via introgression between these two species with parallel annual bloom cycles.

Rhododendron prunifolium exhibited the highest withinspecies diversity (0.41), and this diversity was exhibited not only in the pooled $H_{\mathrm{T}}$ value but also in two random subsamples of three populations $\left(H_{\mathrm{T}}=0.40,0.41\right.$; data not shown), indicating the diversity was not due to the greater number of populations sampled. Phenotypic and habitat variation among populations explains the discrepancy between relatively low within-population genetic diversity $\left(H_{\mathrm{S}}=0.30\right.$; Table 3$)$ and relatively high within-species genetic diversity $(0.41)$ and is supported by a modest correlation between Nei's unbiased genetic distance (Nei, 1978) with geographic distance $(r=$ $0.432, P=0.02)$. Rhododendron prunifolium was the only species in the study to show a significant correlation $(P \leq 0.05)$ of genetic distance and geographic distance (data not shown). Parapatric speciation may explain this result, although a much broader sampling of populations will be required to determine if this phenomenon is present. Rhododendron prunifolium and $R$. flammeum are the two most phenotypically variable species included in this study. Rhododendron flammeum principally inhabits hardwood forest ecosystems and displays increased phenotypic variation within individual populations. Conversely, $R$. prunifolium exhibits greater phenotypic diversity among populations and inhabits a wide variety of ecological niches, ranging from upland hardwood forests at the northern species range to stream basins at the southern range. Greater phenotypic variation observed among populations, coupled with diverse habitat preference across the species range, suggests that some level of genetic divergence is occurring along the north-south axis of $R$. prunifolium's geographic range.

Rhododendron canescens also exhibited a relatively high level of within-species variation (0.40). The level of variation among populations of $R$. canescens was unexpected as phenotypically the species is very stable. There are two possible explanations for these results. Because of the broad geographic range of $R$. canescens, the largest of any member of section Pentanthera, a small upward bias in within-species diversity may be expected as species with broad ranges generally exhibit higher $H_{\mathrm{T}}$ values. The relatively higher level of variation may also be the result of past interspecific hybridization (introgression) events with a number of related species. The geographic ranges of four separate species with similar annual flowering times overlap three of the collection sites of $R$. canescens. The 
Meriwether County, GA, and Baldwin County, GA, populations are within the range of R. flammeum; the Bullock County, $\mathrm{GA}$, population is within the $R$. atlanticum range; and the Lee County, AL, population is within the ranges of Rhododendron alabamense Rehder (Small) and Rhododendron cumberlandense E.L. Braun (Kron, 1993). The introgression of even a single individual in past generations of these populations could be the cause of a slight upward bias in within-species diversity, despite the lack of phenotypic evidence, as introgression would have introduced variable genetic material into each of the populations surveyed.

EFFECTS OF CLONAL STRUCTURE ON DIVERSITY ESTIMATES. $H_{\mathrm{S}}$ and $H_{\mathrm{T}}$ values of $R$. atlanticum were intermediate to other species in this study. However, the $G_{\mathrm{ST}}$ value for $R$. atlanticum is low at 0.10 (Table 3). Rhododendron atlanticum is the only species incorporated into this study that forms dense clonal patches. In the populations surveyed for this study, multiple genotypes formed interconnecting patches with minimal breaks. Because of dense cover, it is likely that seedling germination or survival is low within the bounds of the colonized area. This plant habit was possibly the result of a founder effect. Population genesis likely occurred when one or several plants intermated and colonized the habitable area surrounding the introduction site. Such phenomena, observed in the related species, Rhododendron ferrugineum L. (Wolf et al., 2004), prevents the introduction of alleles from other populations or species, leading to genetically diverse yet highly related individuals that share a majority of alleles due to common ancestry.

EVIDENCE OF INTROGRESSION BASED ON GENETIC DISTANCE COMPARISONS. As expected, Nei's unbiased genetic distances (Nei, 1978) among populations were lower within species compared with among species (Table 5). Additionally, the phenogram derived from Nei's unbiased genetic distances (Fig. 1) provided expected grouping of species into individual branches based on the accepted morphological key generated by Kron (1993). Only four of the 25 populations surveyed in this study showed distinct signs of introgression (Table 5; Fig. 1). Genetic distance indices for $R$. prunifolium fall into two distinct groups (Table 5). The three populations collected from the southern area of the species range are highly related, with indices of 0.10 to 0.11 . The three northern populations are also highly related, with values of 0.07 to 0.09 . A comparison of genetic distances between populations of the northern and southern groups show less relatedness among the two sets of populations (0.21-0.24). Remarkably, these values are similar to those across species in this study. When genetic distances are visualized as a UPGMA phenogram (Fig. 1), the dissociation between northern and southern populations is evident. Northern populations occupy an independent branch-point of the phenogram, while southern populations share a major branch with $R$. austrinum populations. This is corroborated by genetic distance indices between southern $R$. prunifolium populations and $R$. austrinum populations that range from 0.08 to 0.12 (Table 5). These genetic distance values are extremely low for between-species comparisons and closely resemble values seen within a species. This was unexpected, considering that all populations were phenotypically verified at several growth stages and that the two species exhibit distinct flowering periods, with $R$. austrinum flowering 2-3 months before $R$. prunifolium.

Despite present-day morphologic differences, major climate shifts possibly led to an intermingling of the two species' geographic range or annual flowering period. Studies suggest the occurrence of such an event in woody cross-pollinated species native to the eastern United States. Two examples are Liquidambar styraciflua $\mathrm{L}$. and Liriodendron tulipifera $\mathrm{L}$. that purportedly migrated south to the Gulf of Mexico coast at the period of glacial maxima of the Pleistocene period (Hoey, 1990; Parks et al., 1994). In the case of $R$. prunifolium, any migration southward of the species during this same geologic period would intermingle at least the southern populations of $R$. prunifolium with existing $R$. austrinum populations. Breeders should be aware of the genetic, morphologic, and habitat differences between southern and northern populations when breeding with $R$. prunifolium.

Within-species genetic diversity of three populations of $R$. canescens was similar to that of other species in this study (0.04-0.05; Table 5), with the exception of a single population located in Bullock County, GA (0.26-0.28). The phenogram of genetic distances (Fig. 1) groups this population in a major branch shared with $R$. viscosum and a minor branch with only the Bullock County, GA, R. viscosum population. These two populations are located $6 \mathrm{~km}$ apart, an acceptable distance on the basis of our collection parameters and considering differential bloom periods. Yet it appears that introgression has occurred at some time between the two populations, possibly the result of severe drought or significant late freeze/cold weather pattern. During a severe drought in central Georgia during 2001-2002, the researchers witnessed no flowering in two populations of $R$. viscosum in Harris and Meriwether counties, GA, in Summer 2002. Spring 2003 brought nearnormal rainfall, and plants in each population began sporadically flowering in mid-March, 2 months before normal bloom time. Such an event could align the flowering periods and may explain these results. As genetic diversity is very low within species, relatively few hybrid individuals could potentially cause an upward bias in genetic distance values.

Rehder (1921) and Skinner $(1955,1961)$ postulated that naturally occurring interspecific hybridization (introgression) plays an important role in creating and maintaining morphological (and genetic) diversity, and Skinner went further by stating introgression was a major component in the evolution of members of the section Pentanthera. We further propose that introgression within the section Pentanthera serves to reduce inbreeding depression within individual populations, as AMOVA results from this study indicate an extremely low proportion of genetic diversity among populations within species ( $3 \%$, Table 4$)$ and only slightly higher genetic variation among species (14\%). No studies have been conducted in native azaleas to assess the overall vigor of a species or population when introgression is minimized by geographic distance or disjointed flowering time. Yet many studies in other crosspollinated species have noted reductions in population vigor, due to inbreeding depression, within isolated or small populations (Keller and Waller, 2002). Although extremely difficult to measure, the same principle should hold true in larger populations with low allelic diversity. Because members of section Pentanthera primarily outcross and contain low levels of genetic variation among populations of a single species, it is reasonable to assume that a reduction in heterosis would occur in native azalea populations (or species) isolated for multiple generations. Therefore, introgression events would serve to increase heterosis within the population, essentially "rescuing" the population from the effects of inbreeding depression, specifically the fixation of deleterious alleles that reduce 


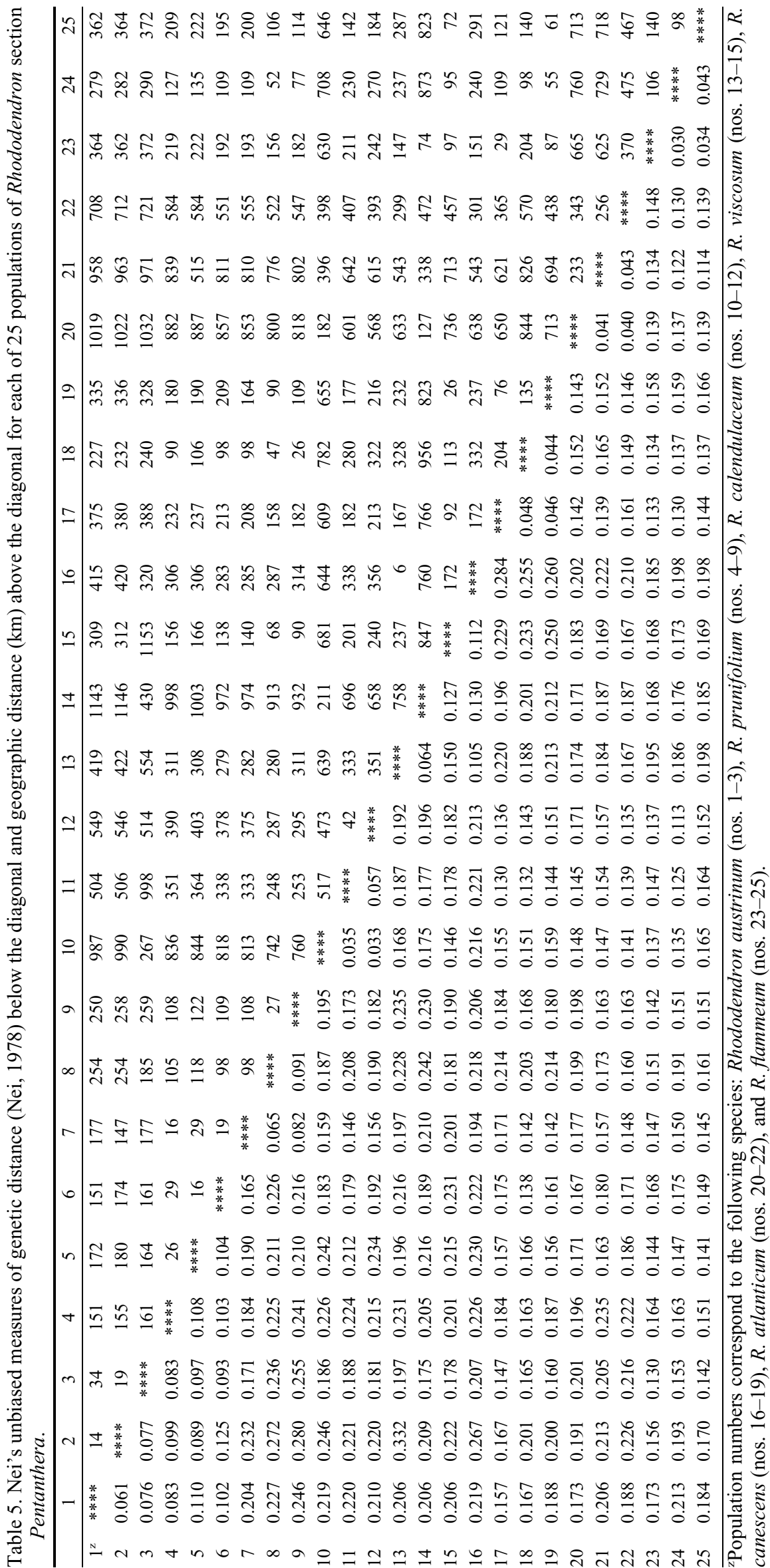




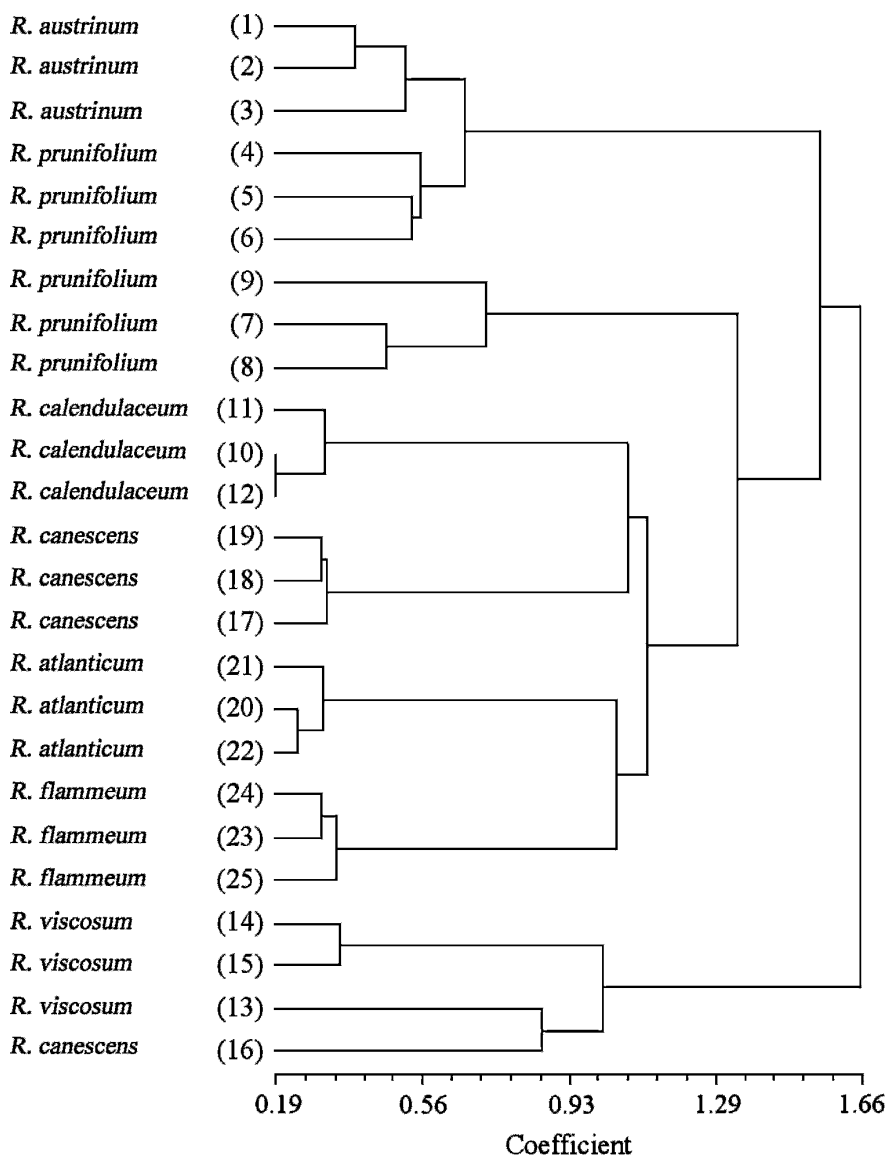

Fig. 1. Dendrogram of Nei's unbiased genetic distance matrix (Nei, 1978) overall 25 Rhododendron section Pentanthera populations surveyed. Populations are denoted in parentheses to the right of species identification. The unrooted dendrogram was constructed using NTSYS (Rohlf, 1992). The neighbor-joining method was used to determine the genetic relationship between populations, applying the Dice similarity coefficient (\%).

fecundity and the ability of a population to adapt to environmental stress or change.

AFLP markers exhibited a high level of efficiency in detecting genetic variation within Rhododendron section Pentanthera. The results of this study indicate that members of Rhododendron section Pentanthera are highly related, both among and within species, despite occupying a vast geographic area. The proportion of variation among species and among populations of each species is low, with the greatest proportion of genetic variation residing within individual populations. When the actual (not proportional) variation of individual species is assessed, in addition to low among-species and among-population diversity, within-population variation is also relatively low.

Three points have been illuminated by this study in relation to the breeding of North American native azaleas. First, breeders should take precautions to ensure that breeding material, if deemed to be a pure species, has not been compromised via introgression. Identification of populations consisting of one species without hybrid individuals, based on phenotypic keys, was difficult in the field. In several instances, multiple observations of phenotypic characters indicated a population consisted of a single species, yet genetic data suggest that introgression had occurred. Second, there is a low level of genetic diversity observed among populations within species. While genetic diversity does exist among populations, the relatively low level of diversity indicates that the importance of collecting individuals from multiple geographically isolated populations to obtain allelic diversity in parent stock is not critical. Third, results illuminate potential pitfalls in the conservation of native azaleas in the eastern United States. The low levels of genetic diversity, coupled with its entomophilous outcrossing nature, suggest that gene flow both among populations and among species (introgression) is important in maintaining the heterosis of populations or species. Fragmentation or isolation of populations due to anthropogenic activity could have a significant and swift negative effect on the health, vigor, and adaptability of individual populations or species. Studies should be conducted to identify those species that may be at risk either due to small geographic range ( $R$. flammeum, $R$. prunifolium) or habitat preferences that collide with development preferences $(R$. atlanticum, $R$. flammeum).

\section{Literature Cited}

Anderson, E. 1949. Introgressive hybridization. Wiley, New York. Barker, J.H., M. Matthes, G.M. Arnold, K.J. Edwards, I. Ahman, S. Larson, and A. Karp. 1999. Characterization of genetic diversity in potential biomass willows (Salix spp.) by RAPD and AFLP analyses. Genome 42:173-183.

Falk, D.A., E.E. Knapp, and E.O. Guerrant. 2001. An introduction to restoration genetics. Soc. Ecol. Restoration, Sci. Policy Paper No. 1.

Galle, F.C. 1967. Native and some introduced azaleas for southern gardens: Kinds and culture. Amer. Hort. Mag. 46:13-23.

Galle, F.C. 1987. Azaleas. Timber Press, Portland, OR.

Hamrick, J.L. and M.J.W. Godt. 1996. Conservation genetics of endemic plant species, p. 281-304. In: J.C. Avise and J.L. Hamrick (eds.). Conservation genetics. Chapman and Hall, New York.

Hoey, M.T. 1990. Patterns of genetic divergence within the vicariad genus Liquidambar L. (Hamamelidaceae). Univ. North Carolina, Chapel Hill, PhD Diss.

Holsinger, K.E. 1999. Analysis of genetic diversity in geographically structured populations: A Bayesian perspective. Hereditas 130:245255.

Holsinger, K.E., P.O. Lewis, and D.K. Dey. 2002. A Bayesian approach to inferring population structure from dominant markers. Mol. Ecol. 11:1157-1164.

Iqbal, M.J., D.W. Paden, and A. Lane-Rayburn. 1995. Assessment of genetic relationships among Rhododendron species, varieties, and hybrids by RAPD analysis. Scientia Hort. 63:215-223.

Jones, C.J., K.J. Edwards, S. Castaglione, M.O. Winfield, F. Sala, C. van de Wiel, G. Bredemeijer, D. Vosman, M. Matthews, A. Daly, R. Brehschneider, P. Bettini, M. Buiatti, E. Maestri, A. Malcevschi, N. Marmiroli, R. Aert, G. Volckaert, J. Rueda, R. Linacero, A. Vazquez, and A. Karp. 1997. Reproducibility testing of RAPD, AFLP and SSR markers in plants by a network of European laboratories. Mol. Breeding 3:381-390.

Kalinowski, S.T. 2005. Do polymorphic loci require large sample sizes to estimate genetic distances? Heredity 94:33-36.

Keller, L.F. and D.M. Waller. 2002. Inbreeding effects in wild populations. Trends Ecol. Evol. 17:230-241.

Kron, K.A. 1993. A revision of Rhododendron section Pentanthera. Edinburgh J. Bot. 50:249-362.

Kron, K.A., L.M. Gawen, and M.W. Chase. 1993. Evidence for introgression in azaleas (Rhododendron; Ericaceae): Chloroplast DNA and morphological variation in a hybrid swarm on Stone Mountain, Georgia. Amer. J. Bot. 80:1095-1099.

Kurashige, Y., J.I. Etoh, T. Handa, K. Takayanagi, and T. Yukawa. 2001. Sectional relationships in the genus Rhododendron (Ericaceae): 
Evidence from matK and trnK intron sequences. Plant Syst. Evol. 228:1-14.

Li, H. 1957. Chromosome studies in the azaleas of eastern North America. Amer. J. Bot. 44:8-14.

Nei, M. 1978. Estimation of average heterozygosity and genetic distance from a small number of individuals. Genetics 89:583-590.

Nei, M. 1987. Molecular evolutionary genetics. Columbia Univ. Press, New York.

Parks, C.R., J.F. Wendel, M.M. Sewell, and Y.-L. Qiu. 1994. The significance of allozyme variation and introgression in the Liriodendron tulipifera complex (Magnoliaceae). Amer. J. Bot. 81: 878-889.

Rehder, A. 1921. The azaleas of North America, p. 107-196. In: E.H. Wilson and A. Rehder (eds.). A monograph of azaleas Rhododendron subgenus Anthodendron. Theophrastus, Providence, RI.

Rohlf, F.J. 1992. NTSYS-pc numerical taxonomy and multivariate analysis system. Version 1.70. Exeter Software, Setauket, NY.

Saitou, N. and M. Nei. 1987. The neighbor-joining method: A new method for reconstructing phylogenetic trees. Mol. Biol. Evol. 4:406-425.

Sax, K. 1930. Chromosome stability in the genus Rhododendron. Amer. J. Bot. 17:247-251.

Scharff, R.E. 1911. Distribution and origin of life in America. Constable, London.

Scheiber, S.M., R.L. Jarret, C.D. Robacker, and M. Newman. 2000. Genetic relationships within Rhododendron L. Section Pentanthera G. Don based on sequences of the internal transcribed spacer (ITS) region. Scientia Hort. 85:123-135.
Schneider, S., D. Roessli, and L. Excoffier. 2000. Arlequin: A software for population genetics data analysis. Version 2.000. Genetics and Biometry Laboratory, Department of Anthropology, Univ. Geneva, Geneva, Switzerland.

Skinner, H.T. 1955. In search of native azaleas. Morris Arboretum Bul. 6.

Skinner, H.T. 1961. Classification of native American azaleas. Amer. Rhododendron Soc., Portland, OR, May 1961. Proc. Intl. Rhododendron Conf. 81-86.

Vos, P., R. Hogers, M. Bleeker, M. Reijans, T. van de Lee, M. Hornes, A. Frijters, J. Pot, J. Peleman, and M. Kuiper. 1995. AFLP: A new technique for DNA fingerprinting. Nucleic Acids Res. 23: 4407-4414.

Wherry, E.T. 1943. The American azaleas and their variations. Natl. Hort. Mag. 22:158-166.

Winfield, M.O., G.M. Arnold, and F. Cooper. 1998. A study of genetic diversity in Populus nigra subsp. betulifolia in the Upper Severn area of the UK using AFLP markers. Mol. Ecol. 7:3-10.

Wolf, P.G., B. Doche, L. Gielly, and P. Taberlet. 2004. Genetic structure of Rhododendron ferrugineum at a wide range of spatial scales. J. Hered. 95:301-308.

Yeh, F.C., R.C. Yang, T.B.J. Boyle, Z.H. Ye, and J.X. Mao. 1999. POPGENE 3.2, the user-friendly shareware for population genetic analysis. Mol. Biol. Biotechnol. Ctr., Univ. Alberta, Edmonton.

Zerr, T. and S. Henikoff. 2005. Automated band mapping in electrophoretic gel images using background information. Nucleic Acids Res. 33:2806-2812. 